\title{
Good Feasibility of the New German Blood Donor Questionnaire
}

\author{
Claudia Houareau ${ }^{a}$ Robert Deitenbeck ${ }^{b}$ Ariane Sümnig ${ }^{c} \quad$ Anette Moeller $^{d}$ \\ Christiane Saadé $\quad$ Frank Stötzer $^{f}$ Margarethe Heiden $^{g}$ Hinnak Northoff ${ }^{\mathrm{h}}$ Ruth Offergeld ${ }^{\mathrm{a}}$
}

\footnotetext{
a Department of Infectious Disease Epidemiology, Robert Koch Institute, Berlin, Germany;

${ }^{b}$ German Red Cross Blood Donation Service West, Hagen, Germany;

${ }^{\mathrm{c}}$ Institute for Immunology and Transfusion Medicine, University Greifswald, Greifswald, Germany;

${ }^{d}$ Institute for Immunology and Transfusion Medicine, University Gießen, Gießen, Germany;

${ }^{\mathrm{e}}$ Institute for Laboratory Medicine, Transfusion Medicine and Microbiology, Helios Clinic, Pforzheim, Germany;

${ }^{f}$ German Red Cross Blood Donation Service Baden-Württemberg-Hessen, Mannheim, Germany;

gDepartment for Transfusion Medicine, Paul Ehrlich Institute, Langen, Germany;

${ }^{\mathrm{h}}$ Center for Clinical Transfusion Medicine, ZKT, University of Tübingen, Tübingen, Germany
}

\section{Keywords}

Blood donors · Donor selection · Blood donor questionnaire

\section{Summary}

Background: We assessed the effect of the uniform donor questionnaire (UDQ) on deferral rates in first-time and repeat donors. We focused on the introduced question about unprotected sexual contact with a new partner. Another goal was a stratified comparison of the deferral rates of the donor questionnaire (DQ) and UDQ. Methods: Data on donors and deferrals using the DQ and UDQ were collected at four blood establishments. The comparison included a 2-year period by questionnaire version. For the comparison of the questionnaires, an adjusted multinomial logistic regression was performed. Results: The analysis included 260,848 donations. First-time (FTD) and repeat donations (RD) showed higher deferral rates with the UDQ (FTD $+5.4 \%$, RD $+1.4 \%$ ). Deferral due to a new partner was $3.0 \%$ in firsttime and $0.4 \%$ in repeat donors. The majority of these occurred in the youngest age groups. The most frequent deferral criterion was 'disease' (5.1\%). Conclusion: The regression revealed stronger predictors for deferral than the questionnaire version. Especially younger age carried a higher and independent risk for deferral. The additional deferrals of mainly young first-time donors due to a new sexual partner may identify those donors with potential heterosexual risk behavior who would otherwise not be identified.

(C) 2017 S. Karger GmbH, Freiburg

\section{Introduction}

The selection of healthy donors is crucial to maintain the existing high level of blood safety. Thus, the donor questionnaire (DQ) becomes an important part of the donor selection process. In Germany, at present, different questionnaires are in use due to the de-centralized structure of the blood supply [1]. All DQs fulfil the criteria required by the German Hemotherapy Guidelines and regulations of the competent authority [2]. To optimize the quality of the DQ, a group on behalf of the National Advisory Committee 'Blood' developed a uniform DQ (UDQ) which aimed to be as simple as possible, comprehensible, accepted by donors, and effective in selecting low-risk healthy donors $[1,3]$. Special attention was paid to (hetero-)sexual risk behavior. A new question on unprotected sexual contact with a new partner within the 4 months preceding the donation was introduced. Results of a first evaluation of the newly developed UDQ showed that especially young male firsttime donors were deferred due to a new sexual partner [3]. This raised the concern that many donors, including repeat donors, could be lost if the UDQ become mandatory, especially within the younger donor population. This concern was addressed in a second multicenter trial with a larger sample size including first-time and repeat donors.

The goal of this study was to determine the effect of the UDQ on deferral rates in first-time and repeat donors. We focused on the effects of the newly introduced question about unprotected sexual contact with a new partner. In a second step, we made a stratified comparison of deferral rates between the UDQ and the DQ.

\section{KARGER}

(c) 2017 S. Karger GmbH, Freiburg

Fax +497614520714 


\section{Material and Methods}

\author{
Call for Participants
}

All blood establishments (BE) in Germany were invited to participate in the study via the homepage of the National Competent Authority (Paul Ehrlich Institute). Different levels of data entry for deferrals were offered to the participants of the study. All data were stratified for sex, age group (18-24 years; 25-34 years; $35-44$ years; $45-54$ years; $>54$ years), and donor status (first-time or repeat donor).

The following levels of data entry were used by the BE which participated in the study:

1) Deferrals were reported on an individual level differentiating between temporary and permanent deferrals. Reasons for deferral were summed in ten categories: disease (which included surgery, medication, vaccination, and all types of medical treatment or underlying conditions); risk for CreutzfeldtJacob disease (CJD) and variant CJD; pregnancy and breast feeding; physical examination; travel-associated risks; sexual risk behavior (except for new partner); unprotected sexual contact with a new partner within the 4 months preceding the donation; injecting drug use; tattoo, piercing, needle stick injury; other reasons.

2) Deferrals were reported as aggregated data. Within this level of data entry, five categories for deferral (new partner, disease, travel-associated, tattoos, and sexual risk behavior) were used. These data were also stratified for sex, age group, and donor status.

Both levels included the number of successful donations and the number of confidential unit exclusions (CUE) stratified for sex, age group, and donor status.

\section{Study Participants}

Our multicenter study was conducted between 2009 and 2013 at the following four BE: German Red Cross Blood Service West, Hagen (BSD West); Department for Transfusion Medicine, University of Greifswald; Institute for Immunology and Transfusion Medicine, Medical University Gießen and Marburg; Institute for Laboratory Medicine and Transfusion Medicine, Helios Hospital Pforzheim.

All BE submitted their data generated using the UDQ. In addition, two BE (BSD West, Gießen/Marburg) added comparative data using the DQ (table 1). Retrospectively, BSD West submitted data sets based on the 2 years preceding the study when the established DQ was used.

\section{Statistical Analyses}

The analysis was based on donations. The aggregated data on successful donations were imputed to individual data. Differences on descriptive level were analyzed with the chi-square test according to Pearson. Throughout statistical analyses, we aggregated temporary and permanent deferral into one deferral variable. We excluded CUE cases from any regression analyses. To further investigate the contribution of the newly introduced category 'new partner', we performed multinomial logistic regression. We employed multinomial logistic regression analysis to estimate deferral within the UDQ in the following categories: new partner, disease, tattoos, and other reasons depending on sex and age group. The base outcome was successful donation. Interactions between sex and age group were included to characterize possible risks for deferral. We adjusted regression analysis for sex, age group, and donor status. For sex, age group, and donor status, we used donations from female donors, age group 35-44 years, and donations from repeat donors as reference categories. Since we found an overall effect of first-time donation, we limited the model to repeat donations and adjusted it for sex and age group as described above.

For the comparison of DQ and UDQ, one BE (BSD West) gathered information fit for the adjusted multinomial logistic regression. The comparison of DQ and UDQ was adjusted with regard to sex, age group, and questionnaire version (DQ as reference category). The comparison did not include the deferral category 'new partner' since this category did not exist in the established DQ. All regression results are reported in relative risks and their significant contribution to the model. We compared 2 years with the DQ versus 2 years with the UDQ. P values $<0.05$ were considered significant.

All analyses were performed using STATA ${ }^{\circledR} 14.1$ (StataCorp LP, College Station, TX, USA)

\section{Results}

Of all participating BE, data of 261,016 donations entered the study. Missing data summed up to $0.1 \%$ of the total sample size. All remaining 260,848 donations were included into the analysis (99.9\%). These included 145,965 (55.9\%) donations collected with the UDQ. Two sites applied both questionnaires (BSD West and Gießen/Marburg). At the BSD West the UDQ rate was $49.1 \%$, and at Giessen/Marburg it was $39.0 \%$ of all donations.

\section{Descriptive Analysis}

The deferral rate in the four study sites ranged from $9.4 \%$ in repeat donations to $34.7 \%$ in first-time donations. A CUE was made in $0.3 \%$ of all donations, irrespective of donor status. Details are presented in table 2 .

\section{Reasons for Deferral}

Of all deferral categories applied in this study, 'disease' showed the highest deferral rate in first-time (13.8\%) and repeat donations (3.7\%). Deferral rates for all categories are listed in table 3.
Table 1. Overview of the period and questionnaires applied by study participants

\begin{tabular}{lll}
\hline Study site & Questionnaire & Time period \\
\hline BSD West & DQ & $\begin{array}{l}16.05 .2009-15.05 .2011 \\
16.05 .2011-15.05 .2013\end{array}$ \\
\hline Gießen/Marburg & UDQ & $18.04 .-23.05 ., 06.06 .-10.06 .2011$ \\
& DQ & $24.05 .-02.06 ., 14.06 .-21.06 ., 08.07 .-13.07 .2011$ \\
\hline Greifswald & UDQ & $01.06 .2011-31.12 .2011$ \\
\hline Pforzheim & UDQ & $01.10 .2011-31.12 .2012$ \\
\hline
\end{tabular}


Table 2. Deferrals with the UDQ by study site and donor status $(\mathrm{n}=145,965)$

\begin{tabular}{llllll}
\hline Study site & Donor status & Total & Deferral (\%) & CUE (\%) & Successful donations (\%) \\
\hline BSD West & FTD & 17,423 & $6,619(38.0)$ & $38(0.2)$ & $10,766(61.8)$ \\
& RD & 90,907 & $10,107(11.1)$ & $302(0.3)$ & $80,498(88.6)$ \\
Marburg & FTD & 230 & $22(10.5)$ & $2(0.9)$ & $206(89.6)$ \\
Greifswald & RD & 1,500 & $32(2.1)$ & $4(0.3)$ & $1,464(97.6)$ \\
& FTD & 1,523 & $301(19.8)$ & $15(1.0)$ & $1,207(79.3)$ \\
Pforzheim & RD & 17,216 & $1,329(7.7)$ & $48(0.3)$ & $15,839(92.0)$ \\
& FTD & 1,174 & $193(16.4)$ & $0(0.0)$ & $981(83.6)$ \\
& RD & 15,992 & $316(2.0)$ & $1(0.0)$ & $15,675(98.0)$ \\
& FTD & 20,350 & $7,135(34.7)$ & $55(0.3)$ & $13,160(64.7)$ \\
& RD & 125,615 & $11,784(9.4)$ & $355(0.3)$ & $113,476(90.3)$ \\
& all & 145,965 & $18,919(13.0)$ & $410(0.3)$ & $126,636(86.8)$ \\
\hline \multirow{2}{*}{ FTD = First-time donation; RD = repeat donation; CUE = confidential unit exclusion. } &
\end{tabular}

Table 3. Descriptive of deferral categories of the UDQ $(\mathrm{n}=145,965)$

\begin{tabular}{|c|c|c|c|}
\hline \multirow[t]{2}{*}{ Deferral category } & \multicolumn{3}{|l|}{ Donor status } \\
\hline & FTD (\%) & RD (\%) & All (\%) \\
\hline Successful donation & $13,160(64.7)$ & $113,476(90.3)$ & $126,636(86.8)$ \\
\hline Disease & $2,809(13.8)$ & $4,588(3.7)$ & $7,397(5.1)$ \\
\hline Examination & $1,522(7.5)$ & $3,973(3.2)$ & $5,495(3.8)$ \\
\hline Tattoos & $1,057(5.2)$ & $737(0.6)$ & $1,794(1.2)$ \\
\hline New partner & $616(3.0)$ & $532(0.4)$ & $1,148(0.8)$ \\
\hline Travel associated & $149(0.7)$ & $302(0.2)$ & $451(0.3)$ \\
\hline Injecting drug use $\mathrm{e}^{\#}$ & $167(0.8)$ & $59(0.1)$ & $226(0.2)$ \\
\hline Sexual risk behavior & $79(0.4)$ & $41(0.0)$ & $120(0.1)$ \\
\hline Pregnancy $^{\#}$ & $55(0.3)$ & $52(0.0)$ & $107(0.1)$ \\
\hline CJD/ vCJD & $28(0.1)$ & $13(0.0)$ & $41(0.0)$ \\
\hline Other $^{\#}$ & $653(3.2)$ & $1,487(1.2)$ & $2,140(1.5)$ \\
\hline Total & 20,355 (100.0) & $125,615(100.0)$ & $145,965(100.0)$ \\
\hline
\end{tabular}

The two youngest age groups revealed the highest deferral due to a new partner: $2.1 \%(531 / 25,403)$ of all donations of 18 - to 24 -year-old donors and $1.4 \%(452 / 32,050)$ of all donations of 25 to 34-year-old donors were deferred. Stratified for donor status, deferrals of male first-time donors were significantly higher than deferrals of female first-time donors within the same age groups (18- to 24-year-old donors: chi-square $(1)=35.5 ; \mathrm{p}<0.01 ; 25$ - to 34 -year-old donors: chi-square $(1)=34.0 ; \mathrm{p}<0.01)$ Details are shown in figure 1.

\section{Multinomial Logistic Regression Model}

The adjusted multinomial logistic regression model to identify risk factors for deferral showed an overall effect of first-time donations (chi-square $(5)=5748.93, \mathrm{p}<0.01)$. Therefore, we limited the model to repeat donations, which constitute $86.1 \%$ of all donations applying the UDQ $(125,615 / 145,965)$.

\section{Relative Risks of Deferral due to Newly Introduced Category}

'New Partner'

Results of the final model revealed: Donations of the two youngest age groups had a three (18-24 years) and two times (25-34 years) higher expected risk of exclusion due to 'new partner' $\left(\mathrm{RR}_{18-}\right.$ 24 years $\left.=3.06, \mathrm{p}<0.01 ; \mathrm{RR}_{25-34 \text { years }}=2.45, \mathrm{p}<0.01\right)$. The two oldest age groups had significantly lower expected risks of being deferred by indicating unprotected intercourse with new sexual partner within the preceding 4 months $\left(\mathrm{RR}_{45-54 \text { years }}=0.38, \mathrm{p}<0.01 ; \mathrm{RR}_{>54}\right.$ years $=0.08, \mathrm{p}<0.01)$. Neither sex nor the interaction of sex and age group significantly contributed to the estimation of deferral in the category 'new partner' regarding repeat donations.

\section{Influence of Sex}

Within the categories 'disease', 'tattoos', and 'other', female donors had an expected higher risk of deferral (disease: $\mathrm{RR}_{\text {male }}=$ $0.67, \mathrm{p}<0.01$; tattoos: $\mathrm{RR}_{\text {male }}=0.45, \mathrm{p}<0.01$; other: $\mathrm{RR}_{\text {male }}=0.48$, $\mathrm{p}<0.01)$. 


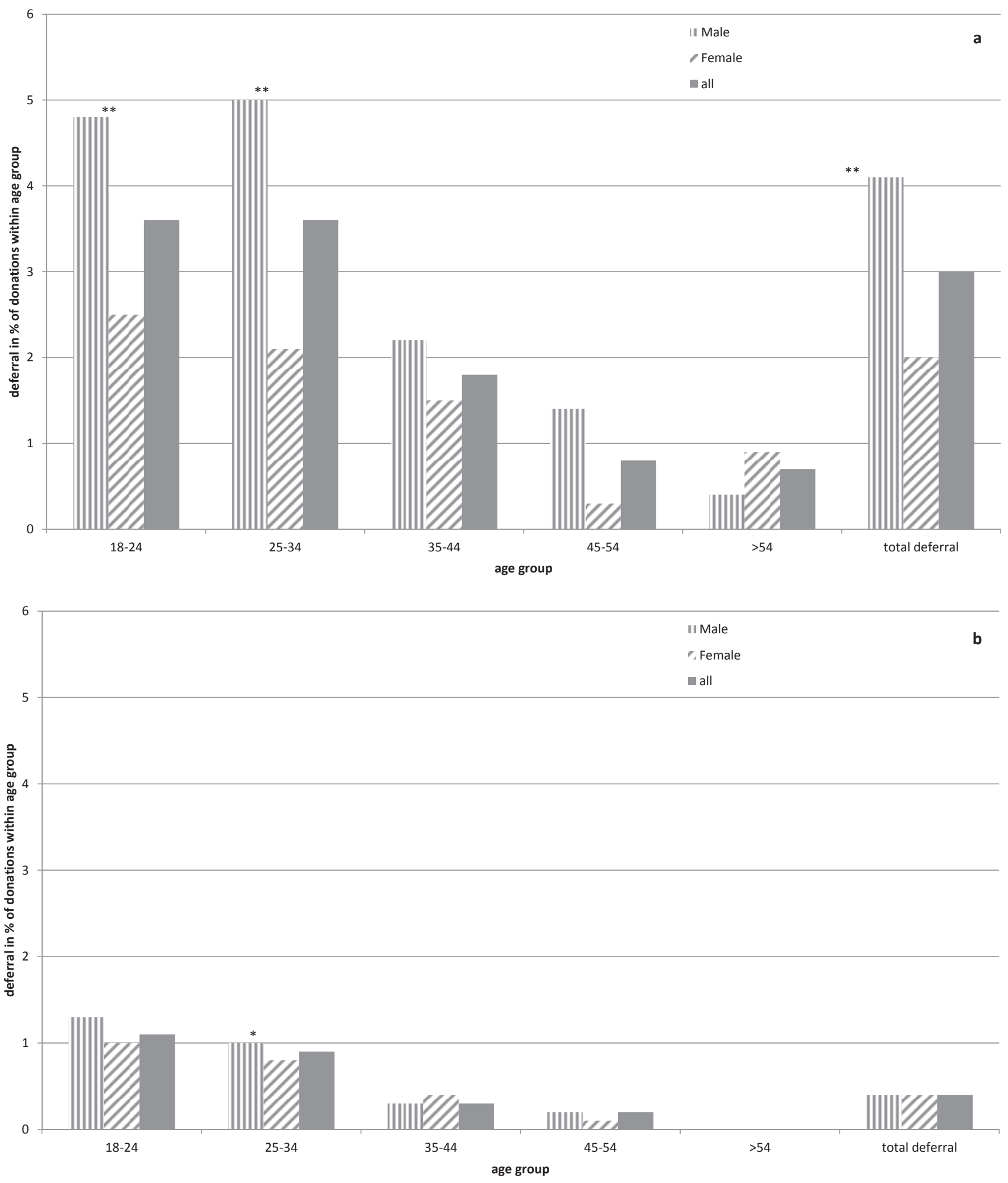

Fig. 1. a Proportion of deferral due to 'new partner' in first-time donors ( $n=20,355$ donations). b Proportion of deferral due to 'new partner' in repeat donors $(n=125,615)$. 
Table 4. Sociodemographic characteristics $(\mathrm{n}=219,559)$

\begin{tabular}{|c|c|c|c|c|}
\hline & \multicolumn{2}{|l|}{ DQ } & \multicolumn{2}{|l|}{ UDQ } \\
\hline & $\begin{array}{l}\text { RD } \\
(\mathrm{n}=93,141)\end{array}$ & $\begin{array}{l}\text { all } \\
(\mathrm{n}=112,176)\end{array}$ & $\begin{array}{l}\text { RD } \\
(\mathrm{n}=90,510)\end{array}$ & $\begin{array}{l}\text { all } \\
(\mathrm{n}=107,383)\end{array}$ \\
\hline \multicolumn{5}{|l|}{$\operatorname{Sex}(\%)$} \\
\hline Female & 42.0 & 43.7 & 42.2 & 44.0 \\
\hline \multicolumn{5}{|l|}{ Age groups (\%) } \\
\hline $18-24$ years & 1.9 & 6.1 & $7.8^{* *}$ & $13.8^{\star *}$ \\
\hline 25-34 years & 22.2 & 26.7 & $19.6^{\star *}$ & $21.2^{\star *}$ \\
\hline $34-44$ years & 11.9 & 11.5 & 12.0 & 11.7 \\
\hline $45-54$ years & 24.8 & 22.1 & 24.8 & 22.3 \\
\hline$>54$ years & 39.2 & 33.7 & $35.7^{* *}$ & $31.0^{* *}$ \\
\hline
\end{tabular}

Table 5. Deferrals according to the UDQ versus DQ by donor status (excluding category 'new partner') $(n=219,559)$

\begin{tabular}{|c|c|c|c|c|c|c|}
\hline \multirow[t]{2}{*}{ Deferral category } & \multicolumn{3}{|c|}{ DQ $(n=112,176)$} & \multicolumn{3}{|c|}{ UDQ $(n=107,383)$} \\
\hline & FTD & $\mathrm{RD}$ & all & FTD & $\mathrm{RD}$ & all \\
\hline Examination & $1,555(8.15)$ & $3,210(3.45)$ & $4,765(4.25)$ & $1,412(8.37)$ & $3,210(3.55)$ & $4,622(4.30)$ \\
\hline Other & $629(3.30)$ & $1,4321(1.54)$ & $2,060(1.84)$ & $576(3.41)$ & $1,283(1.42)$ & $1,859(1.73)$ \\
\hline Tattoos & $1,115(5.86)$ & $709(0.76)$ & $1,824(1.63)$ & $1,037(6.15)$ & $683(0.75)$ & $1,720(1.60)$ \\
\hline IDU & $162(0.85)$ & $38(0.44)$ & $200(0.18)$ & $166(0.98)$ & $59(0.07)$ & $225(0.21)$ \\
\hline Sexual risk & $57(0.30)$ & $18(0.21)$ & $75(0.07)$ & $72(0.43)$ & $29(0.03)$ & $101(0.09)$ \\
\hline Pregnancy & $48(0.25)$ & $68(0.07)$ & $116(0.10)$ & $54(0.32)$ & $46(0.05)$ & $100(0.09)$ \\
\hline CJD/vCJD & $51(0.27)$ & $22(0.02)$ & $73(0.07)$ & $27(0.16)$ & $11(0.01)$ & $38(0.04)$ \\
\hline Total deferral & $5,820(30.6)$ & $8,646(9.3)$ & $14,466(12.9)$ & $6,069(36.0)^{\star *}$ & $9,710(10.7)^{\star *}$ & $15,779(14.7)^{\star \star *}$ \\
\hline CUE & $43(0.2)$ & $340(0.4)$ & $383(0.3)$ & $38(0.2)^{\text {n.s. }}$ & $302(0.3)^{\text {n.s. }}$ & $340(0.3)^{\text {n.s. }}$ \\
\hline
\end{tabular}

$\mathrm{DQ}=$ Donor questionnaire; UDQ = uniform DQ; FTD = first-time donation; RD = repeat donation; CUE = confidential unit exclusion; IDU = injecting drug use; ${ }^{* *} \mathrm{p}<0.01 ;$ n.s. $=$ not significant.

\section{Influence of Age Group}

As in the category 'new partner', we found in 'tattoos' and 'other' a highly significant expected risk of the two youngest age groups to be deferred (tattoos: $\mathrm{RR}_{18-24 \text { years }}=2.06, \mathrm{p}<0.01 ; \mathrm{RR}_{25-34}$ years $=1.47, \mathrm{p}<0.01$; other: $\mathrm{RR}_{18-24 \text { years }}=1.79, \mathrm{p}<0.01 ; \mathrm{RR}_{25-34 \text { years }}$ $=1.57 ; \mathrm{p}<0.01)$ while the two oldest age groups showed a highly significant lower expected risk to be deferred within these categories (tattoos: $\mathrm{RR}_{45-54 \text { years }}=0.51, \mathrm{p}<0.01 ; \mathrm{RR}_{>54 \text { years }}=0.22, \mathrm{p}<$ 0.01 ; other: $\mathrm{RR}_{45-54 \text { years }}=0.76, \mathrm{p}<0.01 ; \mathrm{RR}_{>54 \text { years }}=0.63, \mathrm{p}<0.01$ ). In contrast to these results, within the category 'disease' only donations of 25- to 34-year-old donors have a higher expected risk for deferral due to 'disease' (disease: $\mathrm{RR}_{25-34 \text { years }}=1.33, \mathrm{p}<0.01$ ).

For all categories, we found interactions between sex and age group in the category 'other' only; indicating lower risks for deferral due to 'other' in donations of men within the two youngest age

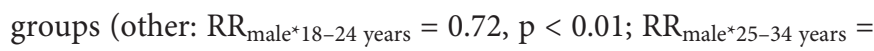
$0.70 ; \mathrm{p}<0.01)$. Donations of men within the eldest age group show higher expected risk for deferral within the category 'other'

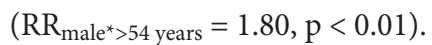

\section{Comparison of the DQ and the UDQ}

Of 260,848 data sets, 219,559 (84.2\%) were from one BE (BSDWest) using both questionnaire versions and all deferral categories each over a 2-year period: $112,176(51.1 \%)$ with the DQ and 107,383 (48.9\%) with the UDQ (table 4).

Female donors were more often deferred than male donors in both questionnaires (UDQ: female $19.7 \%$ vs. male: $12.2 \%$; chisquare $(1)=1,300 ; \mathrm{p}<0.01$; DQ: female $16.8 \%$ vs. male $9.9 \%$; chisquare $(1)=1,200 ; \mathrm{p}<0.01)$. However, there were no sex differences in deferrals between questionnaire versions (chi-square $(1)=$ $0.00 ; \mathrm{p}>0.05)$.

The overall deferral rate increased with the UDQ by $1.8 \%$. Especially, first-time donors had a 5.4\% higher deferral rate (table 5). This is mainly attributed to the deferral category 'disease'. Deferrals due to pregnancy, travel, and sexual risk behavior, increased by less than $0.3 \%$ with the UDQ. CUE did not differ between questionnaire versions (chi-square $(1)=0.02 ; \mathrm{p}>0.05$ ); irrespective of donor status. However, in both questionnaires male first-time donors used CUE more frequently than female first-time donors (UDQ: chisquare $(1)=16.13 ; \mathrm{p}<0.01$; DQ: chi-square $(1)=4.03 ; \mathrm{p}<0.05)$. 


\section{Adjusted Multinomial Logistic Regression}

Adjusted multinomial logistic regression was confined to the group of repeat donations due to an overall effect of first-time donors (chi-square $(4)=6284.87, \mathrm{p}<0.01 ; 80.4 \%(176,589 / 219,559)$.

\section{Influence of Questionnaire Version}

Donors using the UDQ had a higher expected risk of deferral in the category 'disease' $\left(\mathrm{RR}_{\mathrm{UDQ}}=1.5 ; \mathrm{p}<0.01\right)$ than donors using the DQ regardless of age and sex. On the other hand, donors using the DQ had a higher expected risk of deferral in the categories 'tattoos' $\left(\mathrm{RR}_{\mathrm{UDQ}}=0.87, \mathrm{p}<0.01\right)$ and 'other' $\left(\mathrm{RR}_{\mathrm{UDQ}}=0.92, \mathrm{p}<0.01\right)$ independent of age and sex.

\section{Influence of Sex}

Women showed significantly higher expected risks for deferral in the categories 'disease' and 'tattoos' independent of questionnaire version and age group (disease: $\mathrm{RR}_{\text {male }}=0.72, \mathrm{p}<0.01$; tattoos: $\mathrm{RR}_{\text {male }}=0.59, \mathrm{p}<0.01$ ).

\section{Influence of Age Group}

In almost all categories the two youngest age groups were at a higher expected risk of exclusion independent of sex and questionnaire version (disease: $\mathrm{RR}_{18-24}$ years $=1.2, \mathrm{p}>0.05 ; \mathrm{RR}_{25-34}$ years $=$

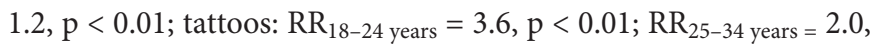
$\mathrm{p}<0.01$; other: $\mathrm{RR}_{18-24 \text { years }}=1.5, \mathrm{p}<0.01 ; \mathrm{RR}_{25-34 \text { years }}=1.2$, $\mathrm{p}<0.05$ ), whereas donations of the two oldest age groups were less likely to be excluded (disease: $\mathrm{RR}_{45-54 \text { years }}=0.9, \mathrm{p}<0.05 ; \mathrm{RR}_{>54}$ years $=0.8, \mathrm{p}<0.01 ;$ tattoos: $\mathrm{RR}_{45-54 \text { years }}=0.6, \mathrm{p}<0.01 ; \mathrm{RR}_{>54 \text { years }}=0.2$, $\mathrm{p}<0.01$; other: $\mathrm{RR}_{45-54 \text { years }}=0.7, \mathrm{p}<0.01 ; \mathrm{RR}_{>54 \text { years }}=0.7, \mathrm{p}<01$ ).

\section{Influence of Sex and Age Group}

Within the category 'disease' men aged 18-24 years were at risk for deferral $\left(\mathrm{RR}_{\text {male }^{*} 18-24 \text { years }}=1.3, \mathrm{p}<0.05\right)$.

\section{Discussion}

Donor selection is an important step in maintaining the high level of safety for donor and recipient. The presented study assessed deferral rates in first-time and repeat donors when a recently developed uniform UDQ was used. We focused on the effect of the introduced question about a new sexual partner. Additionally, we compared the UDQ with the established DQ.

We found an overall deferral rate of $13.0 \%$ with the new UDQ. This rate was similar to comparable studies: In the literature, about $10-15 \%$ of applicant donors are deferred due to the DQ [4-6]. Still, in comparison to the established DQ, we found an increase in deferrals by $5.4 \%$ and $1.4 \%$ in first-time and repeat donations respectively. These additional deferrals were mainly due to higher deferral rates in the category 'disease'. This corresponds well to the results of the previous DQ study in which the UDQ was evaluated in a multicenter trial with 6,500 first-time donors [3]. The category 'disease' included medical treatment of any kind or underlying medical conditions. Donor deferral due to this category is intended to reduce the risk of undetected transfusion-transmissible infections (TTI) or to assure donor health $[7,8]$. Therefore, we consider the moderate increase in deferrals due to medical treatment or conditions to be of benefit with respect to blood and donor safety.

An essential innovation in the UDQ was the introduction of a question regarding unprotected intercourse with a new sexual partner in the 4 months preceding the donation. This question addressed heterosexual risk behavior as sex between men lead to a permanent deferral according to the German Hemotherapy Guidelines [2]. In recent analyses, undisclosed heterosexual contacts revealed to be a risk factor for TTI (Preußel, personal communication; [9-12]). In Germany, an analysis demonstrated that unreported heterosexual risks were more prevalent in HIV- or HCVinfected blood donors than in cases from the general population (Preußel, personal communication). According to this study, the identification of all heterosexual risk contacts might prevent acceptance of $53 \%$ of HIV-infected donors. A further study of undisclosed risk behavior in HIV-positive donors in Italy revealed heterosexual risk contacts in 68.1\% [9]. Another retrospective analysis of pre-donation screening revealed acute $\mathrm{HBV}$ infections in donors reporting new heterosexual partners [11]. Also in the UK, there were more reported heterosexual exposures among infected blood donors (both with and without a partner with an identifiable risk) in 2014 than in the previous year, while other reported exposure like sex between men decreased [12]. The UK blood donor surveillance report showed that 18 of 24 donors with a recent infection were infected by heterosexual contacts. Of these, 4 male and $3 \mathrm{fe}-$ male donors reported one or more new partners. Also, like in Germany, a rise in recent syphilis infections among new donors, especially heterosexual men, was observed in the UK [12]. The rise was most prominent in young male donors but also seen - to a lesser extent - in young female donors, which could imply a rise in (hetero-)sexual risk behavior.

Heterosexual risk behavior was addressed in former DQs using leading questions about, e.g., 'one-night stands', 'casual contacts', or 'frequent change of partner'. These questions partly left the risk assessment to the donor. However, recent studies confirmed that in post-donation interviews, the majority of HIV-positive donors did not realize they engaged in risk behavior $[9,10,13]$. Therefore, a precise definition of heterosexual risk behavior would be desirable. Attempts to make this definition failed with exception of highrisk behavior like sex work [14]. Therefore, in the conception of the UDQ, we decided to address heterosexual exposure (unprotected sexual contact with a new partner prior to the donation) rather than making an arbitrary definition of heterosexual risk behavior. This procedure is well established in other countries like Spain or Italy [14]. Further advantages of this approach are that a question about sexual contact with a new partner is clear and non-judgmental and leaves little room for interpretation by the donor [3].

The question about a new sexual partner chiefly lead to deferrals of younger first-time donors: On the descriptive level, we found significantly higher deferral rates in the 'new partner' category among male first-time and - to a lesser extent- among repeat donors. If we are controlling for the large sample size by using effect 
sizes, i.e. relative risks, provided by a multinomial logistic regression analysis [15], the indications of higher deferral rates of young male donors did not achieve significance in repeat donations. The multinomial logistic regression showed higher risks for exclusion due to a new sexual partner in the two youngest age groups, independent of sex. The 'new partner' question identified the group which empirically carries the highest risk for TTIs [16]. Thus the 'new partner' question is capable of preventing window period donations of donors with unspecified heterosexual risks.

Still, demographic changes in Germany will most likely lead to fewer younger donors in the future on the one hand and to an increasing need of blood and blood products due to an ageing population on the other $[17,18]$. Therefore, the reasons for deferral need to be clearly communicated to potential donors, and low-risk donors should be recruited continuously in order to provide enough appropriate blood products for patients in need. The recently published first results of the 'donor of the future project' also addressed demographic changes of the donor population and showed the need for new service strategies for future donor recruitment in order to meet the high expectations of donors [19]. Ultimately, the safety gained by rigid and straightforward donor selection for sexual risks must not lead to a disproportional loss of recruited and retained young repeat donors.

In the first UDQ study [3], some donors felt that the character of direct questions about their sexual contacts were too private. Nonetheless, the UDQ was acceptable to the majority of donors [17] and demonstrated its superiority compared to the established DQ regarding comprehensibility as well as donor adherence [3]. Furthermore, results of a cognitive interview evaluation of the new AABB DQ found no evidence that blood donors modified their answers due to a perceived inappropriate sensitive character of questions [10].

The comparison of questionnaire versions did not include the 'new partner' question as it was not asked in the DQ. In the comparative analysis of the remaining categories, the only significant influence of the UDQ on deferral rates was found in the category 'disease'. This was demonstrated on the descriptive level in a previous study [20]. Our regression analysis revealed that the observed higher deferral rates in the category 'disease' were independent of age and sex. The data available for this study did not allow for analysis of underlying reasons for deferral in any category. Still, a comparison of the questionnaires showed that in the DQ almost all medical reasons for deferral were asked in one grouped question. In contrast with the UDQ, it was initially asked whether the donor is feeling sick or is on sick leave. This was followed by a set of grouped questions regarding medical conditions. Furthermore, with the UDQ it was explicitly asked about certain commonly used drugs, i.e. acetylsalicylic acid. Similar reasons for higher deferral rates with the DQ in the category 'tattoos' can be assumed. With the $\mathrm{DQ}$, tattoo, piercing, and needle stick injury were asked in one grouped question with acupuncture, colonoscopy as well as contact to a patient with hepatitis. In contrast to the DQ, the UDQ included separate questions to tattoo, piercing, and needle stick injury. These differences in layout and questions may have led to the above mentioned differences in deferral rates between the two questionnaire versions and warrant further investigations.

Overall, female donors were more often deferred than male with both questionnaires. This has also been observed in other investigations $[20,21]$. However, the regression analysis showed that women were not significantly more often deferred with the UDQ. Also, in almost all categories for deferral the two youngest age groups were at a higher risk of deferral independent of sex and questionnaire version. These results from the regression analyses differed from the results of a previous DQ study [20].

There are limitations with regard to our study: Due to the categorization of reasons for deferral, we were unable to specify precise differences in deferrals. This applied especially to the category 'disease' which includes all types of medical treatment or underlying conditions. The UDQ was offered for nationwide use via the homepage of the competent authority in 2011 together with an invitation to participate in the study. Still, the evaluation was limited to four $\mathrm{BE}$ of which only one was able to provide a complete set of comparative data for the UDQ and the DQ, allowing for regression analysis. Only two university BE participated, and thus it is difficult to predict if the UDQ has specific effects on a predominantly student donor population.

In conclusion, we were able to demonstrate the feasibility of the UDQ in this multicenter study. Most deferrals are due to medical treatment or conditions and ensure blood product safety and donor health. The subsequent higher deferral rates need to be monitored, and appropriate measures need to be taken to ensure the blood supply also in the future. The temporary deferral of individuals with a new heterosexual partner is warranted to deal with non-specified but increasing heterosexual risk behavior among donors. Further studies, including donor perception of questionnaires and correlations with screening results of those who are deferred, will be beneficial. We hope that this work motivates and guides future research in this area.

\section{Acknowledgment}

The authors would like to thank Dr. Schwenz for her support in finishing this manuscript and Mr. Rolf Kessel for his invaluable support in data extraction.

\section{Disclosure Statement}

All authors declare that they have no conflict of interests due to sponsorship or funding arrangements related to this study. 


\section{References}

1 Stellungnahme des AK Blut: Verwendung eines ein heitlichen Fragebogens für Blut- und Plasmaspender Bundesgesundheitsbl Gesundheitsforsch Gesundheitsschutz 2010;53:862-862.

2 Bundesärztekammer: Richtlinien zur Gewinnung von Blut und Blutbestandteilen und zur Anwendung von Blutprodukten (Hämotherapie). Cologne, Deutscher Ärzte-Verlag, 2010.

3 Offergeld R, Heiden M, Stötzer F, Northoff H: Der einheitliche Spenderfragebogen. Hämotherapie 2011;16: 23-27.

4 Zou S, Fujii K, Johnson S, Spencer B, Washington N, Iv EN, Musavi F, Newman B, Cable R, Rios J: Prevalence of selected viral infections among blood donors deferred for potential risk to blood safety. Transfusion 2006;46:1997-2003.

5 Zou S, Musavi F, Notari EP, Fujii KE, Dodd RY: Prevalence of selected viral infections among temporarily deferred donors who returned to donate blood: American Red Cross blood donor study. Transfusion 2005; 45:1593-1600.

6 Custer B, Schlumpf K, Simon TL, Spencer BR, Wright DJ, Wilkinson SL: Demographics of successful, unsuccessful and deferral visits at six blood centers over a 4year period. Transfusion 2012;52:712-721.

7 Lin C, Leung J, So B, Lee C: Donor selection for blood safety: is it still necessary? ISBT Sci Ser 2014;9:26-29.
8 Yang H, Anderson SA, Forshee R, Williams A, Epstein JS, Marks PW. Modeling complete removal of risk assessment questions in the USA predicts the risk of HIV exposure in blood recipients could increase despite the use of nucleic acid testing. Vox Sang 2016;110:324-328.

9 Raimondo M, Facco G, Regine V, Pupella S, Grazzini G, Suligoi B: HIV-positive blood donors unaware of their sexual at-risk behaviours before donation in Italy. Vox Sang 2016;110:134-142.

10 Willson S, Miller K, Seem D, Kuehnert MJ: Cognitive evaluation of the AABB uniform donor history questionnaire. Transfusion 2016;56:1662-1667.

11 Lieshout-Krikke RW, Zaaijer HL, Laar TJ: Predonation screening of candidate donors and prevention of window period donations. Transfusion 2015;55:373-378.

12 Public Health England: Safe Supplies: Annual Review. 2013, last updated November 18, 2016. www.gov.uk/ government/publications/safe-supplies-annual-review (last accessed June 8, 2017)

13 Lucky TT, Seed CR, Waller D, Lee FJ, McDonald A, Wand H, Wroth S, Shuttleworth G, Keller AJ, Pink J, Wilson DP: Understanding noncompliance with selective donor deferral criteria for high-risk behaviours in Australian Blood donors. Transfusion 2014;54:17391749

14 Offergeld R, Kamp C, Heiden M, Norda R, Behr-Gross ME: Sexual risk behaviour and donor deferral in Europe. Vox Sang 2014;107:420-427.
15 Lin M, Lucas HC Jr, Shmueli G: Research commentary - too big to fail: large samples and the p-value problem. Information Systems Research 2013;24:906-917.

16 Offergeld R, Ritter S, Hamouda O: HIV-, HCV-, HBVund Syphilissurveillance unter Blutspendern in Deutschland 2008-2010. Bundesgesundheitsblatt 2012; 55:907-913.

17 Sümnig A, Lembcke H, Weber H, Deitenbeck R, Greffin K, Bux J, Greinacher A: Evaluation of a new German blood donor questionnaire. Vox Sang 2014;106: 55-60.

18 Ritter S, Hamouda O, Offergeld R: Demografie und Spendeaktivität von Blut- und Plasmaspendern in Deutschland. Bundesgesundheitsbl Gesundheitsforsch Gesundheitsschutz 2012;55:914-922.

19 Sundermann L, Kort W, Boenigk S: The 'donor of the future project' - first results and further research domains. Vox Sang 2017; DOI: 10.1111/vox.12484.

20 Müller-Steinhardt M, Weidmann C, Wiesneth M, Weck E, Seifried E, Brade J, Klüter H: Donor deferra rates after the implementation of a new german blood donor questionnaire. Transfus Med Hemother 2012 39:17-22.

21 Misje AH, Bosnes V, Heier H: Gender differences in presentation rates, deferrals and return behaviour among Norwegian blood donors. Vox Sang 2010; 98:e241-e248 